\title{
Grey Bronze Prospecting in the Eastern Region of Yanbian Forecast
}

\author{
Yanying Ma, Xiuzhen Li and Qiang Liu* \\ Jilin Engineering Normal University, Changchun, China, 130052 \\ Izyl068052@126.com \\ *The corresponding author:
}

\begin{abstract}
Keywords: Eastern part of Yanbian area; Multi-Source information; Metallogenic Prognosis; The Grey Relational Analysis
\end{abstract}

\begin{abstract}
Taking the gray relational analysis as research method, this paper made the location prediction of exploration, in the eastern region of Yanbian. The known minimum connection degree unit was used as mother sequence, and 26 unknown units was used as subsequences . We made grey correlation analysis, and found the ore grade of each unit .The grade I units were ; 12,16,21and 29 etc. Finally, the use of integrated information predicted results were compared with the results of this study verification, the two results are basically consistent with satisfactory.
\end{abstract}

\section{The Grey Relational Analysis method and principle}

The grey relational analysis is different from the correlation coefficient, from another Angle between the degree of correlation factors are the measurement method. It according to the sequence of geometric similar degree between the line to measure the relative degree of correlation between factors, is the factors of system dynamic process development situation of quantitative comparison analysis [22].

Mother sequence has

$$
\mathrm{X}=\{x(\mathrm{k})\}, \quad k=1,2,3 \cdots, m
$$

And $\mathrm{n}$ is the sequence

$$
\mathrm{X}_{\mathrm{j}}=\left\{x_{\mathrm{j}}(\mathrm{i})\right\}, \quad \mathrm{i}=1,2,3 \cdots, m ; \mathrm{j}=1,2, \cdots, n
$$

Will they be the initial value, or the mean, normalization, etc, in order to eliminate them with transformation in dimension differences. Unity again after reference point. And the following formula for the mother, the first is the sequence of sequence and the correlation coefficient:

$$
\xi_{0 i}(k)=\frac{\min _{i} \min _{j}\left|x_{0}(j)-x_{i}(j)\right|+\zeta \max _{i} \max _{k}\left|x_{0}(j)-x_{i}(j)\right|}{\left|x_{0}(j)-x_{i}(j)\right|+\zeta \max _{i} \max _{k}\left|x_{0}(j)-x_{i}(j)\right|}
$$

Type of $j=1,2, \cdots, m ; i=1,2, \cdots, n ; \zeta \in[0,1]$ this is distinguish coefficient.

Finally, a correlation coefficient calculation of the mean:

$$
r_{0 i}=\frac{1}{m} \sum_{j=1}^{m} \xi_{0 i}(j), i=1,2, \cdots, n
$$

The first is called mother sequence and sequence of correlation degree. Mother and son sequence sequence will be line charts, their shape, the bigger the more close to the value. To find out the grey relation by sice size, analysis, and judgment, this is for the correlation analysis. 
Geological problems, often the ore-forming geological characteristic similarity research. An unknown area, as long as its various geological characteristics and are known to have mine area are similar, it can be applied the grey relational analysis and geological ore-prospecting work.

\section{Model Using}

In this paper the research is divided into 30 abnormal, among them for five, abnormal known unknown abnormality for 26 . Use gold, copper and evaluation prediction model analysis calculated containing ore unit and unknown known ore potentiality of unit connection degree, see table 1 and table 2 .

Table 1 Degree of cell contact known

\begin{tabular}{|l|l|l|}
\hline Serial number & Unit Numbers & Connection degree \\
\hline $\mathbf{1}$ & 10 & 0.8096 \\
\hline $\mathbf{2}$ & 17 & 0.6795 \\
\hline $\mathbf{3}$ & 20 & 0.645 \\
\hline $\mathbf{4}$ & 31 & 0.5799 \\
\hline $\mathbf{5}$ & 8 & 0.5394 \\
\hline
\end{tabular}

Table 2 Unknown unit connection degree

\begin{tabular}{|c|c|c|c|c|c|}
\hline Serial & Connection & Unit & Serial & Connection & Unit \\
\hline $\mathbf{1}$ & 0.60 & 2 & $\mathbf{1 4}$ & 0.35 & 23 \\
\hline $\mathbf{2}$ & 0.59 & 24 & $\mathbf{1 5}$ & 0.33 & 30 \\
\hline $\mathbf{3}$ & 0.58 & 4 & $\mathbf{1 6}$ & 0.30 & 27 \\
\hline $\mathbf{4}$ & 0.57 & 12 & $\mathbf{1 7}$ & 0.30 & 19 \\
\hline $\mathbf{5}$ & 0.53 & 21 & $\mathbf{1 8}$ & 0.23 & 1 \\
\hline $\mathbf{6}$ & 0.52 & 29 & $\mathbf{1 9}$ & 0.22 & 5 \\
\hline $\mathbf{7}$ & 0.52 & 16 & $\mathbf{2 0}$ & 0.21 & 15 \\
\hline $\mathbf{8}$ & 0.50 & 11 & $\mathbf{2 1}$ & 0.20 & 3 \\
\hline $\mathbf{9}$ & 0.49 & 13 & $\mathbf{2 2}$ & 0.17 & 6 \\
\hline $\mathbf{1 0}$ & 0.49 & 28 & $\mathbf{2 3}$ & 0.17 & 9 \\
\hline $\mathbf{1 1}$ & 0.44 & 14 & $\mathbf{2 4}$ & 0.17 & 22 \\
\hline $\mathbf{1 2}$ & 0.41 & 18 & $\mathbf{2 5}$ & 0.15 & 26 \\
\hline $\mathbf{1 3}$ & 0.39 & 7 & $\mathbf{2 6}$ & 0.10 & 25 \\
\hline
\end{tabular}

Since unit connection degree reveals the metallogenic possibility height, the unit and containing ore unit known as the minimum connection degree in one minerals, so the metallogenic using research will be known as the smallest unit connection degree of metallogenic minimum connection degree, namely for mother sequence. And the rest of the 26 unknown unit as a child, according to the relational sequence calculation steps, and concludes that the correlation calculation results see table 3. 
Table 3 Grey Correlation

\begin{tabular}{|l|l|l|l|l|l|}
\hline $\begin{array}{l}\text { Serial } \\
\text { number }\end{array}$ & $\begin{array}{l}\text { Connection } \\
\text { degree }\end{array}$ & $\begin{array}{l}\text { Unit } \\
\text { Numbers }\end{array}$ & $\begin{array}{l}\text { Serial } \\
\text { number }\end{array}$ & $\begin{array}{l}\text { Connection } \\
\text { degree }\end{array}$ & $\begin{array}{l}\text { Unit } \\
\text { Numbers }\end{array}$ \\
\hline $\mathbf{1}$ & 0.817 & 2 & $\mathbf{1 4}$ & 0.560 & 23 \\
\hline $\mathbf{2}$ & 0.848 & 24 & $\mathbf{1 5}$ & 0.534 & 30 \\
\hline $\mathbf{3}$ & 0.880 & 4 & $\mathbf{1 6}$ & 0.499 & 27 \\
\hline $\mathbf{4}$ & 0.915 & 12 & $\mathbf{1 7}$ & 0.499 & 19 \\
\hline $\mathbf{5}$ & 1 & 21 & $\mathbf{1 8}$ & 0.433 & 1 \\
\hline $\mathbf{6}$ & 0.958 & 29 & $\mathbf{1 9}$ & 0.425 & 5 \\
\hline $\mathbf{7}$ & 0.958 & 16 & $\mathbf{2 0}$ & 0.4179 & 15 \\
\hline $\mathbf{8}$ & 0.884 & 11 & $\mathbf{2 1}$ & 0.409766 & 3 \\
\hline $\mathbf{9}$ & 0.851 & 13 & $\mathbf{2 2}$ & 0.389 & 6 \\
\hline $\mathbf{1 0}$ & 0.851 & 28 & $\mathbf{2 3}$ & 0.389 & 9 \\
\hline $\mathbf{1 1}$ & 0.718 & 14 & $\mathbf{2 4}$ & 0.389 & 22 \\
\hline $\mathbf{1 2}$ & 0.656 & 18 & $\mathbf{2 5}$ & 0.3768 & 26 \\
\hline $\mathbf{1 3}$ & 0.621 & 7 & $\mathbf{2 6}$ & 0.348 & 25 \\
\hline
\end{tabular}

The golden copper mineral known unit in the smallest unit connection degree with unknown unit value of grey correlation degree draw up the gray relational degree graphs, which indicates unit, and on the basis of metallogenic change law of grey correlation curvilinear characteristic curve, the DouBian slow by, or by slow change steep point mutations, as a bit above or below mutations are shown as possible, so the curve mutations consistency as a metallogenic may differences at the turning point. Setting out the level of mineralization, can put the gold copper unit level as the following: the metallogenic setting

(1) $\mathrm{D}>0.915$ : I level (2) $0.817<\mathrm{D}<0.915$ : II level(3) $\mathrm{D}<0.817$ :III c level

I level unknown unit and the known unit correlation, also has the largest ore prospects in further ore-prospecting preferred, unit. II levels of metallogenic may I level after, has some of the ore propects.III level research area is unknown unit and the known unit correlation smaller units, the level of metallogenic may small metallogenic prospects, further work.

Based on above level assessment criterion and table metallogenic 2-3, unknown forecasting results are as follows: unit

I level units including 12 , no. 16, no. 21, 29, etc.; II level units including 2, 4, 11, 13, no. 24, 28, etc.;

III level units including 1, 3, 5, and 6, 7, 9, number 14, 15 number, number 18, 19, and 22, 23, 25, 26, 27 and 30, etc.

\section{Interpretation of Achievements}

Feature Analysis. According to jilin province in eastern TongWuKuang gold in yanbian forecast report [10], we will result analysis of characteristics of the income and the forecasting area metallogenic level institute for the division of level of grey correlation degree compared 3-(see table 1), visible results of this study has six unit: 2, 4, 16, 21, 24 and 29 units classification level does not agree with the original results, with the remaining $80.7 \%$ unit level with the original results coincide, 
this shows the grey relation analysis evaluation level in this study metallogenic with certain feasibility.

Table 4 Mineral prediction District Bronze and Grey Relational Analysis evaluation of rating list

\begin{tabular}{|l|l|l|c|c|l|l|l|}
\hline $\begin{array}{c}\text { Unit } \\
\text { Numbers }\end{array}$ & $\begin{array}{l}\text { Unit } \\
\text { types }\end{array}$ & $\begin{array}{l}\text { Charact-eristic } \\
\text { s analysis level }\end{array}$ & $\begin{array}{l}\text { The grey } \\
\text { relat-ional } \\
\text { analysis }\end{array}$ & $\begin{array}{l}\text { Unit } \\
\text { Numbers }\end{array}$ & $\begin{array}{l}\text { Unit } \\
\text { types }\end{array}$ & $\begin{array}{l}\text { Charact-eristic } \\
\text { s analysis level }\end{array}$ & $\begin{array}{l}\text { The grey } \\
\text { relat-ional } \\
\text { analysis }\end{array}$ \\
\hline $\mathbf{1}$ & Unknow & III & III & $\mathbf{1 7}$ & known & I & \\
\hline $\mathbf{2}$ & Unknow & I & II & $\mathbf{1 8}$ & Unknow & III & III \\
\hline $\mathbf{3}$ & Unknow & III & III & $\mathbf{1 9}$ & Unknow & III & III \\
\hline $\mathbf{4}$ & Unknow & I & II & $\mathbf{2 0}$ & known & I & \\
\hline $\mathbf{5}$ & Unknow & III & III & $\mathbf{2 1}$ & Unknow & II & I \\
\hline $\mathbf{6}$ & Unknow & III & III & $\mathbf{2 2}$ & Unknow & III & III \\
\hline $\mathbf{7}$ & Unknow & III & III & $\mathbf{2 3}$ & Unknow & III & III \\
\hline $\mathbf{8}$ & known & I & & $\mathbf{2 4}$ & Unknow & I & II \\
\hline $\mathbf{9}$ & Unknow & III & III & $\mathbf{2 5}$ & Unknow & III & III \\
\hline $\mathbf{1 0}$ & known & I & & $\mathbf{2 6}$ & Unknow & III & III \\
\hline $\mathbf{1 1}$ & Unknow & II & II & $\mathbf{2 7}$ & Unknow & III & III \\
\hline $\mathbf{1 2}$ & Unknow & I & I & $\mathbf{2 8}$ & Unknow & II & II \\
\hline $\mathbf{1 3}$ & Unknow & II & II & $\mathbf{2 9}$ & Unknow & II & I \\
\hline $\mathbf{1 4}$ & Unknow & III & III & $\mathbf{3 0}$ & Unknow & III & III \\
\hline $\mathbf{1 6}$ & Unknow & II & I & & & & \\
\hline
\end{tabular}

Multi-source Information. According to jilin province in eastern TongWuKuang gold in yanbian forecast report [10] the prediction results OuJinTong mineral evaluation result comprehensive level table 4, with grey relational analysis level carries on the comparison, seven units can be found with the original results hierarchy is not consistent with, among them for: 4, 11, 12 and 16, 23, 28 and 29 unit $(7 / 31=0.225)$, but the research institute of the hierarchy to three levels, and the original results using level 4 classification principles, this also is produced one of the important reasons for the error. So, in two results, in contrast, only 16 number and 28 is larger, the rest in unit each unit level results with the original results accord with basic, reflect the results of the authenticity and reliability. Therefore, we will grey relation analysis is used to predict the division of metallogenic district level possesses operability, but also for the metallogenic prediction provides a reference method.

\section{Conclusion}

The grey System Theory (Gray System by deng julong keep) is a professor in the early '1980 s, was founded used in every field. Geology is no exception. Its main advantage is:

1. Using the correlation analysis of previous studies of random variables with the correlation between statistics is correlation coefficient, correlation coefficient is mainly from static analysis of random variables, not from the relationship between between variables and time (or the distance) sequence in the comparison of the change process analysis. It is research or inspection factors related degree between linear, in most of the nonlinear relationship is powerless. And grey correlation analysis was based on the geometric similar sequence line between degree to measure the relative degree of correlation between factors, is the factors of system dynamic process development situation of quantitative comparison analysis.

2. The gray system model to sample size not too many requirements, also do not need to obey the typical distribution, very suitable for the mineralization prediction. In system data quantity is little and conditions are not met the requirements of the statistics, the more practical value.

3. The method is simple, easy to accept the theory, the application more convenient. 
4. Using the theory of gray systems to the gray relational degree can be a mining area or a mineral metallogenic mechanism analysis, make didn't clear of the geological factors MingXianHua metallogenic regularity study, play a guiding role.

5. For unit, or the initial value of different different sequence for correlation degree analysis, general will be processing, make the dimensionless, rules of a change.

\section{References}

[1] Fei Zhong-hua, Wang Jing-gui, Huo Jian-ping. The Prediction of Granite-Type Gold Deposits by the Application of Relational Analysis [J], Journal of East China Geological Institute, 1994, 17(3):249-253.

[2] JIN Wei,JIA Xue-min. Application of Grey Correlation Degree for Predicting Target Areas in Gold Deposits[J].Journal of Hebei College of Geology, 1992,15(2):223-228.

[3] Zuo Dairong. Application of gray correlation analysis method in quality evaluation of remaining recoverable reserves [J].Fault-block Oil and Gas Field, 2010,17(3):354-356.

[4] XUE Shun-rong, XIAO Ke-yan, DING Jian-hua. Multi-source Information Metallogenic Prognosis with Weighting of Evidence Based on MRAS in Shangri-La, Journal of Jilin University: Earth Science Edition, 2008, 38(5) : 738-0744.

[5] Xu Zhong-xiang, Wu Guo-ping, Zhou Xin-liang .Grey Correlated Analytical Method for Predicting Gold Deposits[J], China University of Geosciences,

[6] Ma Zhi-yong; Cheng Rong-shu. Application of Grey System to the Evaluation and Prediction of Geological Anomaly for Fine Disseminated Gold Ddpsits in Western Jiangxi[J]. Geological Exploration for Non-ferrous Metals, 1994, 3(5):312-316.

[7] Zhi Dong-sheng; Lin Bao-zeng; Zhu Duo-lu. Applications of Grey System to the Prediction for Ore Deposits. Journal of Guilin College of Geology, 1991,1(2): 191-198. 